\title{
Yawning reduces facial temperature in the high-yawning subline of Sprague-Dawley rats
}

Jose R. Eguibar ${ }^{1,2^{*}}$, Carlos A. Uribe ${ }^{2}$, Carmen Cortes ${ }^{2}$, Amando Bautista ${ }^{3}$ and Andrew C. Gallup ${ }^{4}$

\begin{abstract}
Background: Yawning is a stereotyped behavior that enhances blood flow to the skull, and the resulting counterflow has been hypothesized as a mechanism for brain cooling. Studies have shown that yawns are strongly associated with physiological and pathological conditions that increase brain temperature, and that they are followed by equivalent decreases in brain temperature. However, measured reductions in cranial or facial temperatures following yawning have yet to be reported, to our knowledge. To accomplish this, we used a subline of Sprague-Dawley rats that yawn at a much greater rate (20 yawns/h) than do outbred Sprague-Dawley rats (2 yawns/h).

Results: Using an infrared camera, we effectively evaluated thermal changes in the cornea and concha of these rats before, during, and after yawns. The maximum temperature in both regions significantly decreased $10 \mathrm{~s}$ following yawns (concha: $-0.3{ }^{\circ} \mathrm{C}$, cornea: $-0.4^{\circ} \mathrm{C}$ ), with a return to basal temperatures after $20 \mathrm{~s}$.

Conclusions: This study is the first clear demonstration of yawning-induced thermal cooling on the surface of the face, providing convergent evidence that this behavior plays a functional role in thermoregulation. As other studies have demonstrated that yawning is capable of reducing cortical brain temperature, our current data support the idea that yawning functions as a thermoregulator, affecting all structures within the head.
\end{abstract}

Keywords: Thermoregulation, Head cooling, Thermography, Brain circulation, Grooming, Anxiety

\section{Background}

Yawning is an innate behavior characterized by a stereotyped motor pattern. Wide opening of the mouth and wide dilation of the pharynx and larynx is followed by deep inspiration that ends abruptly with a short expiration. Neck musculature then shrinks and returns to basal levels $[1,2]$. Understanding the physiological significance of yawning is important because spontaneous yawning is ubiquitous in vertebrates [3], with reports identifying atypical yawning as a symptom or side-effect of several neurological diseases or medications [4]. Many hypotheses have been proposed regarding the potential physiological functions of yawning; however, they often lack clear physiological evidence [5]. While much of the

\footnotetext{
*Correspondence: jose.eguibar@correo.buap.mx

${ }^{2}$ Institute of Physiology, Benemérita Universidad Autónoma de Puebla, Apdo. Postal 5-66, Col. Prados Agua Azul, 72430 Puebla, Pue., Mexico Full list of author information is available at the end of the article
}

scientific community believed that yawns serve a respiratory function, experimental procedures performed on humans have demonstrated that yawning and breathing are controlled by separate mechanisms [6]. However, other causes such as fatigue, boredom, and sleepiness have been proposed as causes of increased yawning frequency [4]. One recent theory that has gained recent experimental support proposes that yawning is a brain cooling mechanism [7-9].

In homeotherms, brain temperature is determined by three variables: the rate of arterial blood flow, the temperature of arterial blood, and the amount of metabolic heat production [10]. The physical action of yawning can alter the first two variables. Yawning produces significant changes in circulation, including accelerating heart rate by up to 10 additional beats per minute $[11,12]$. The deep inhalation and powerful jaw stretching during a yawn also favors increases in blood flow to the skull [13], and 
the extended contraction of the lateral pterygoid muscle during yawning acts to squeeze blood from the associated plexus [14]. Therefore, the gaping of the jaw and deep inhalation increase arterial blood flow to the brain and enhance venous return, thus acting to remove hyperthermic blood from the skull and simultaneously introduce cooler blood coming from the lungs and extremities. Increased facial blood circulation and associated changes in the ventilation rate are two well-known mechanisms that cool brain temperature $[15,16]$.

The deep inhalation of air that accompanies yawning may also provide counter-current heat exchange by cooling venous blood draining from the nasal and oral orifices that is in close contact with arterial blood supply [16]. Consistent with this view, recent studies in human and non-human primates $[8,17]$ have shown that pharyngeal cooling rapidly and selectively decreases brain and tympanic temperature by cooling the carotid arteries [17]. Furthermore, anatomical investigations in humans have revealed that the thin sinus walls flex when pterygoid musculature contracts during yawning, indicating that the posterior wall of the maxillary sinus serves as an origin for both medial and lateral pterygoid muscle segments [18]. This powerful flexing of the sinus walls has been proposed to ventilate the human sinus system similarly to what occurs in birds [19], providing a second mechanism through which yawning functions in human cerebral cooling. Accordingly, yawning could reduce brain temperature by ventilating the sinus system and promoting the evaporation of the sinus mucosa [20]. The salivation and tearing that accompany yawning could be a third mechanism for cooling, aiding in heat loss through evaporation [8].

Importantly, yawning appears to be constrained to a narrow range of ambient temperature (i.e., a thermal window). Numerous reports have confirmed and replicated the specific thermal window for various species. For heat to dissipate; ambient temperatures must be lower than the body temperature of the subject animal. Thus, as predicted, in warmer environmental situations, yawning did not cool the brain [7-9, 20]. Consistent with models of thermoregulation, variation in ambient temperature elicits predicted fluctuations in yawning frequency in a number of species, including budgerigars [21], rats [22], white-faced capuchin monkeys [23], and humans [20,24].

Initial rises in temperature within this window trigger yawning and other thermoregulatory cooling mechanisms such as panting and behavioral adjustments to reach thermoneutralization. However, as external temperatures continue to rise beyond the thermal window, yawning decreases because counter-current heat exchange becomes less effective. Similarly, yawning is also reduced at extremely cold temperatures, as thermoregulatory cooling responses are no longer necessary [24].

Direct measures of internal temperature in rats and humans have shown that brain and oral temperature rise immediately before the onset of yawns, with corresponding decreases in temperature being observed directly following these events $[9,25]$. One interpretation is that yawns are triggered by elevated temperature inside the skull, and that the physiological consequences of yawning discussed above result in temperature reduction. Consistent with this view, heightened core body temperature following handling-stress has been shown to be correlated with earlier onset and higher frequency of yawning in birds [26], and experimental manipulations designed to promote brain cooling have been shown to diminish yawning frequency in humans [7]. Furthermore, a number of medical conditions and drugs affect yawning and brain/core temperature in reciprocal patterns. Conditions associated with rises in temperature present with increased yawning, while those associated with lower temperatures present with diminished yawning [8]. However, whether yawning reduces the temperature on the surface of the head or in the face remains unclear.

Selective breeding of Sprague-Dawley rats has generated a subline with a higher incidence of spontaneous yawning [27], which is a useful tool for the physiological study of yawning. Yawning frequency (20 yawns/h) in these high-yawning (HY) rats is an order of magnitude higher than in other Sprague-Dawley rats (2 yawns/h) [27-29]. Thus, HY animals allow us an efficient means to evaluate internal and environmental variables that modulate yawning frequency. Indeed, HY rats were used to determine that yawning has a circadian oscillation pattern that includes significantly increased yawning frequency when transitioning from light periods to dark periods [30]. Under constant light conditions, the circadian rhythm of yawning is disorganized, suggesting that this behavior is not endogenously generated [31]. However, restricting food access to just $2 \mathrm{~h}$ per day produced a highly significant increase in yawning frequency. This is because food access can be a predictor of food availability and can produce an anticipatory yawning peak [31].

High-yawning rats allow us to analyze the role of smell on contagious yawning [32]. HY rats are also more sensitive to cholinergic and dopaminergic agents that increase yawning frequency $[33,34]$, and to adrenocorticotrophic hormones and oxytocin neuropeptides [29, 35], indicating a higher sensitivity of these sublines to environmentally and pharmacologically induced yawning.

Based on past findings regarding yawning and thermoregulation, the present study used a thermographic imaging camera to measure temperature changes associated with spontaneous yawning that occurred in the 
cornea and concha of HY rats. The concha is a good candidate structure because the ears dissipate more heat than other head regions and act as a thermal buffer mechanism in many mammalian species. Similar structures such as the cornea play critical roles in thermoregulation, and are frequently called thermal dissipaters because they are responsible for heat exchange and they regulate surface temperature $[36,37]$.

During yawning, the upper airways are ventilated, and this possibly cools the blood in the facial artery, which travels around the mouth and nasal cavities, making terminations around the eye and cooling these structures [7]. Thus, the two anatomical areas that we selected are good candidates for directly detecting temperature change in areas not covered by fur.

\section{Results}

\section{Spontaneous yawning frequency}

Yawning frequency was calculated for each 5-min epoch of the 60-min observation period. The first 5-min epoch had a mean of 0.6 yawns, which increased and stabilized to 3.7 yawns/5-min epoch during the remaining $50 \mathrm{~min}$ of the observation period (Fig. 1). Yawning frequency in the first epoch was significantly different from all others (repeated ANOVA $F_{10}=2.3, P<0.03$, followed by Tukey's test, $P<0.05)$. Importantly during the rise of ambient temperature, yawning frequency also increased, reinforcing the role of this behavior as a brain cooling mechanism. In contrast, yawning frequency was relatively constant during the subsequent intervals when the ambient temperature remained relatively unchanged. This is a prerequisite for evaluating changes in facial temperature closely associated with yawning in time. Because of this, temperature recordings were only evaluated for the period between 10 and 55 min (Fig. 2, orange squares).

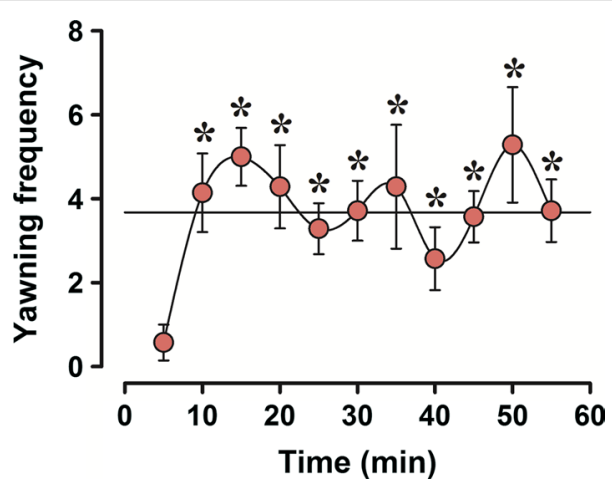

Fig. 1 Higher expression of spontaneous yawning frequency in high-yawning $(\mathrm{HY})$ subline is stable after adaptation period. HY rats yawned 283 times during the observation period (50 min). Yawning frequency was stable between 15 and $55 \mathrm{~min}$, with a mean value of 3.7 yawns $/ 5$ min, being different only in the first 5 -min period with respect to the whole observation period $\left({ }^{*} P<0.05\right)$

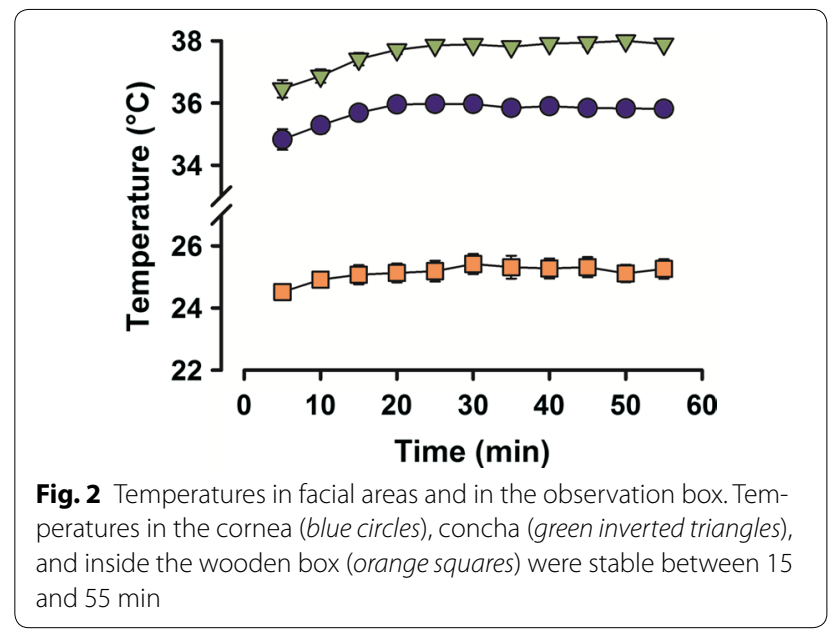

Temperature changes in the facial structures

We recorded 2667 thermographic frames and calculated mean temperature values for the concha and cornea for each 5-min epoch of the observation period. The mean corneal temperature was $34.8 \pm 0.3^{\circ} \mathrm{C}$ in the first epoch, rising $0.1{ }^{\circ} \mathrm{C}$ during the next $15 \mathrm{~min}$ to reach a maximum of $35.8 \pm 0.2{ }^{\circ} \mathrm{C}$, which remained stable for the remainder of the observation period (Fig. 2, blue circles). Corneal temperature during the first epoch was significantly different from the remaining epochs (ANOVA: $\mathrm{F}_{10}=6.9$, $P<0.001$, followed by Tukey's test $P<0.002$, with respect to the first period). The mean conchal temperature was $36.5^{\circ} \mathrm{C}$ in the first epoch, rising to a maximum of $37.9 \pm 0.1{ }^{\circ} \mathrm{C}$ after $20 \mathrm{~min}$ (Fig. 2, green inverted triangles). Conchal temperatures during the first and second epochs were significantly different from those during the fourth through eleventh intervals (ANOVA: $F_{10}=15.5$, $P<0.001$, followed by Tukey's test, $P<0.001$ ).

To have control of variables, we simultaneously measured temperature values inside the wooden observation box at 5-min intervals to evaluate surrounding ambient temperature. The temperature inside the observation box was $24.5 \pm 0.3{ }^{\circ} \mathrm{C}$ during the first epoch and reached a maximum of $25.4 \pm 0.3{ }^{\circ} \mathrm{C}$ after $30 \mathrm{~min}$ (Fig. 2, orange squares). The first epoch was significantly different from the remaining epochs (ANOVA: $\mathrm{F}_{10}=4.3, P<0.001$, followed by Tukey's test, $P<0.03)$. Therefore, as with yawning frequency, temperatures for both facial structures and the surrounding environment increased steeply during the first interval and then became stable for the remaining time periods. Therefore, these intervals were selected for the thermographic analysis associated with yawning.

\section{Correlation between facial temperatures}

To assess the consistency of temperature changes at the two measurement sites, we ran correlation analyses 
between the temperature changes in the cornea and concha across the testing sessions. Additionally, we compared the average temperatures between the left and right cornea. We found a very strong correlation between cornea and conchal temperatures $(\mathrm{r}=0.81, P<0.001$; Fig. 3$)$, and mean temperatures in the right and left cornea were virtually identical $\left(35.5 \pm 0.1{ }^{\circ} \mathrm{C}\right.$ vs. $35.1 \pm 0.1{ }^{\circ} \mathrm{C}$; Student's $t$ test: $\mathrm{t}=0.2, P=0.8)$.

\section{Changes in corneal and conchal temperatures surrounding yawns}

Two hundred and eighty-three yawns were recorded during the testing sessions. The individual yawn counts for the seven rats were as follows $40.4 \pm 4.4$ (mean $\pm \mathrm{SE}$ ). We only analyzed frames in which thermal evaluations were stable across rats and were taken from the same angle $10^{\circ}$, making it possible to compare changes in corneal temperatures (surrounded by black circles) before and after a yawn, as illustrated in thermographic images in Fig. 4.

To homogenize the data, temperatures greater than two standard deviations from the mean $(<5 \%)$ were excluded from the analysis. We compared the data from five time intervals: 20 and $10 \mathrm{~s}$ before the yawn (labeled as -20 and -10 , respectively, Fig. 5), during the yawn (0), $10 \mathrm{~s}$ following a yawn (10), and finally an interval $20 \mathrm{~s}$ following a yawn (20). The total number of frames evaluated in the five periods surrounding yawns were $55,68,56,31$, and 66 .

Predicted changes in facial temperatures occurred surrounding yawning events. All temperatures measured (minimum, mean and maximum) were statistically different across the five time windows at both anatomical sites (cornea ANOVA: $\mathrm{F}_{4}=4.0, P<0.01$; concha ANOVA $\left.\mathrm{F}_{4}=3.6, P<0.01\right)$. Maximum corneal temperatures increased slightly from $35.74 \pm 0.08$ to

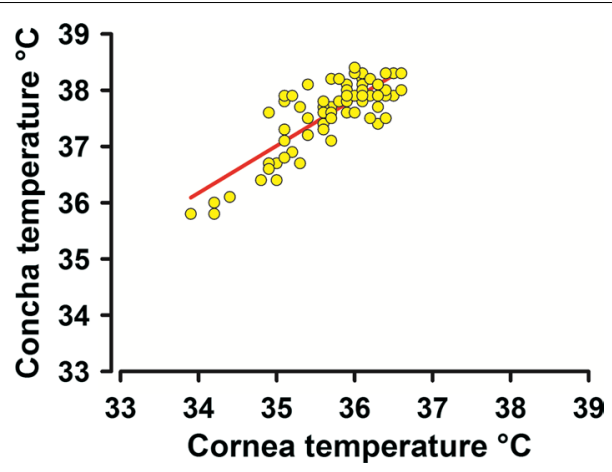

Fig. 3 Correlation between corneal and conchal temperatures during the observation period. During the 45-min observation period, the facial temperatures at the two separate locations were significantly correlated $(r=0.81, P<0.001)$
$35.77 \pm 0.05{ }^{\circ} \mathrm{C}$ (mean $\pm \mathrm{SE}$ ) between 20 and 10 s preceding yawns. Then, temperatures significantly decreased during yawns to $35.61 \pm 0.07{ }^{\circ} \mathrm{C}$ (Tukey's test, $P<0.05$ ), reaching the lowest value of $35.46 \pm 0.13^{\circ} \mathrm{C}$ (Tukey's test, $P<0.05) 10 \mathrm{~s}$ after the yawn. Subsequently, temperatures rose to $35.85 \pm 0.05{ }^{\circ} \mathrm{C}$ by $20 \mathrm{~s}$ after yawns were completed (Fig. 5a). Similarly, maximum conchal temperature rose from $37.20 \pm 0.12$ to $37.45 \pm 0.06{ }^{\circ} \mathrm{C}$ between 20 and $10 \mathrm{~s}$ preceding yawns. Temperatures significantly decreased during yawns to $37.09 \pm 0.13{ }^{\circ} \mathrm{C}$ (Tukey's test, $P<0.05$ : Fig. $5 \mathrm{~b}$ ), reaching the lowest temperature of $36.90 \pm 0.19^{\circ} \mathrm{C}$ (Tukey's test, $\left.P<0.05\right) 10 \mathrm{~s}$ after yawns. Subsequently, by $20 \mathrm{~s}$ after yawns were completed, temperature had increased to $37.3 \pm 0.08^{\circ} \mathrm{C}$.

\section{Discussion}

The use of infrared thermal imaging provides an effective means of tracking behavioral thermoregulation through changes in surface temperature $[36,37]$. This is the first study to document fluctuations in facial temperature that are temporally locked to yawning, revealing that temperatures in the cornea and concha consistently rise leading up to yawning events as shown in Fig. 5b (-10 s) and then decrease below baseline levels shortly thereafter ( $10 \mathrm{~s})$. These results are consistent with previous research measuring changes in brain temperature surrounding yawns in rats [25], and provide further evidence supporting the idea that yawning functions to cool the head and cortical surface [7-9].

Previous reports indicate that yawns are triggered by rises in brain and body temperature [21, 25, 38], which is consistent with the pattern of temperature change we observed preceding yawns. This is illustrated in Fig. 5b, in which $10 \mathrm{~s}$ before a yawn occurs, there is a small increase in the concha temperature that drops significantly during and $10 \mathrm{~s}$ after yawning. This is likely because this area is more exposed to thermal influences, as has already been demonstrated in other species [36, 37]. Because rat brain temperature is consistently higher than that of the arterial blood supplying the brain [39], increases in arterial blood flow and enhanced venous return that result from the act of yawning (i.e., wide opening of the mouth and deep inhalation) could explain the cooling we observed within $10 \mathrm{~s}$ of yawning. Heat convection by blood depends on several variables, including the volume and velocity of blood flow in the vessels [40]. For example, increased blood-flow velocity can result in a twofold increase in heat transmission by tissue [41], and specific reductions in brain temperature have been observed because of increased localized blood flow [42]. Therefore, the decreased temperatures that we observed at the corneal and conchal surfaces are consistent with various models of bio-heat transfer that take perfusion rates into account [43-46]. 

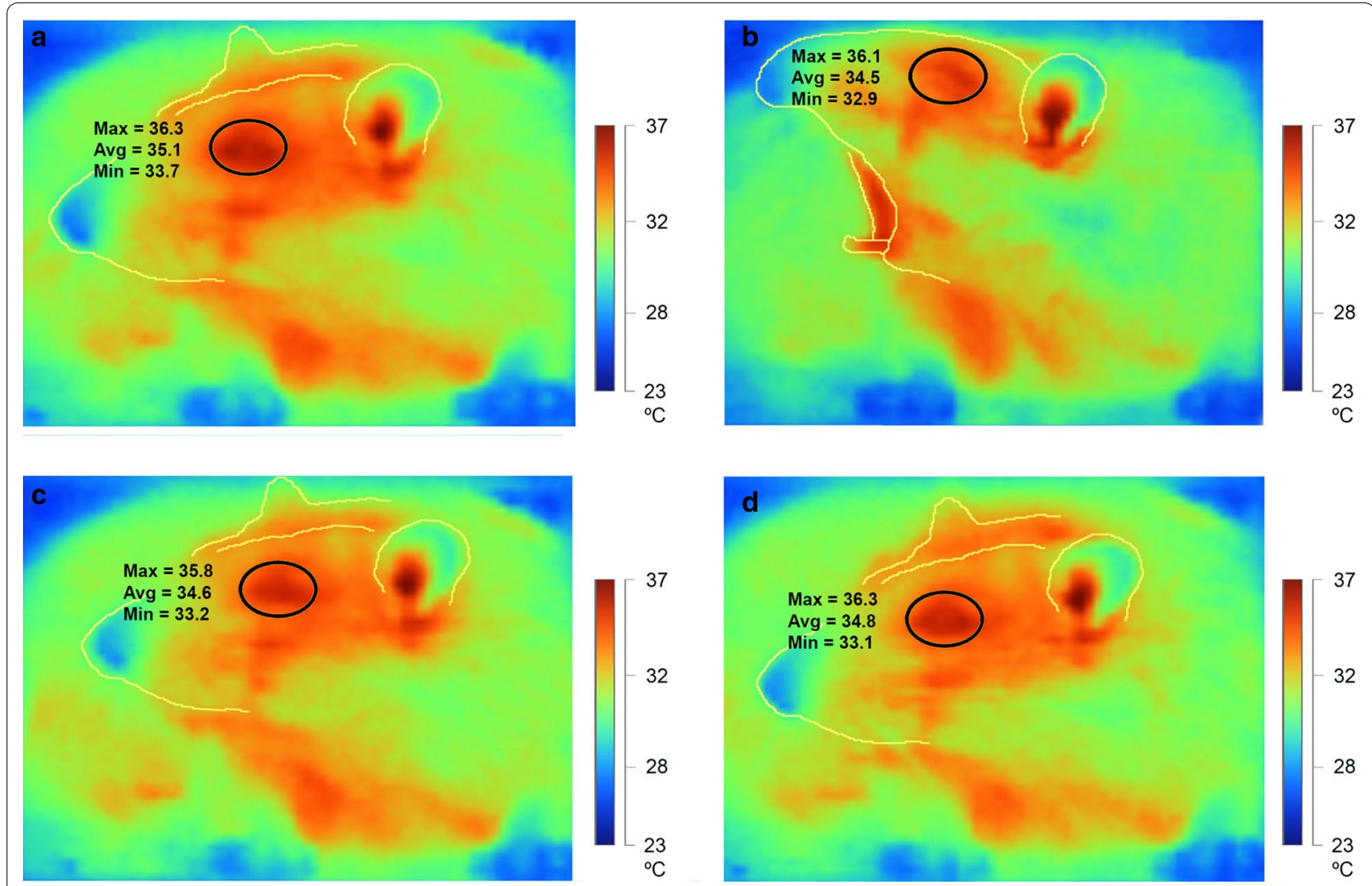

Fig. 4 Representative corneal temperature changes during yawning using a thermographic camera. Serial thermographic pictures before, during and after a yawn. Black circles surrounding the cornea demonstrate the areas in which all measurements were taken. $\mathbf{a} 10 \mathrm{~s}$ before the onset of the yawn, the maximum (Max) temperature in the cornea was $36.3^{\circ} \mathrm{C}$. b When yawning, the Max temperature in the cornea dropped to $36.1^{\circ} \mathrm{C}$. $\mathbf{c}$ After $10 \mathrm{~s}$, the temperature dropped even further, reaching the lowest Max temperature of $35.8^{\circ} \mathrm{C}$. $\mathbf{d}$ After an additional $20 \mathrm{~s}$. Max temperature returned to the basal level at $36.3^{\circ} \mathrm{C}$. Temperature scale bars are on the right side of each panel

We must emphasize that the main heat regulator in rats and mice is the tail. However, facial surface area is also a well-known heat dissipater $[47,48]$. Indeed, in humans, the eyeball-and in particular the cornea, iris, and sclera-are structures with high temperature conductivity because they often have higher temperatures than the environment [49]. Therefore, these eye structures function as thermal dissipaters that work through heat convection, and even evaporation, because tears allow the transmission of heat from inside the cranium to the surface of the eye [49].

The decreases in surface temperature at the cornea and concha sites correspond with previously documented changes in brain-tissue temperature following yawning events in rats. Shoup-Knox et al. [25] showed that temperature in the prelimbic cortex rise sharply just before yawns and then begin to drop after about $18 \mathrm{~s}$, with maximum cooling occurring at about $60 \mathrm{~s}$ following this transition. This time course is much longer than what we observed externally on the eye and the ear, and metabolic heat production from neuronal activity inside the skull should interact with other structures and blood flow that can be responsible, at least in part, for the delayed responses. Together, these observations provide a consistent timeline for a functional role of yawning in cooling the brain, with temperature reductions at external surfaces preceding those at internal brain tissue. It is valid, therefore, to mention that both phenomena share common mechanisms and are temporally linked. Additional experiments are necessary to establish a causal relationship.

Cooling of external surfaces in the head might also contribute to cooling of internal tissues. In humans, the ophthalmic vein, like other emissary veins, has been reported to play an important role in cerebral cooling and may even reverse blood flow depending on the temperature conditions of the environment. Therefore, during hypothermia, blood travels from the brain to the surface of the face, whereas during hyperthermia the opposite pattern occurs [50]. Because yawning in rats and humans has already been demonstrated to be triggered by increases in brain and oral temperature $[25,38]$, cooling of external 

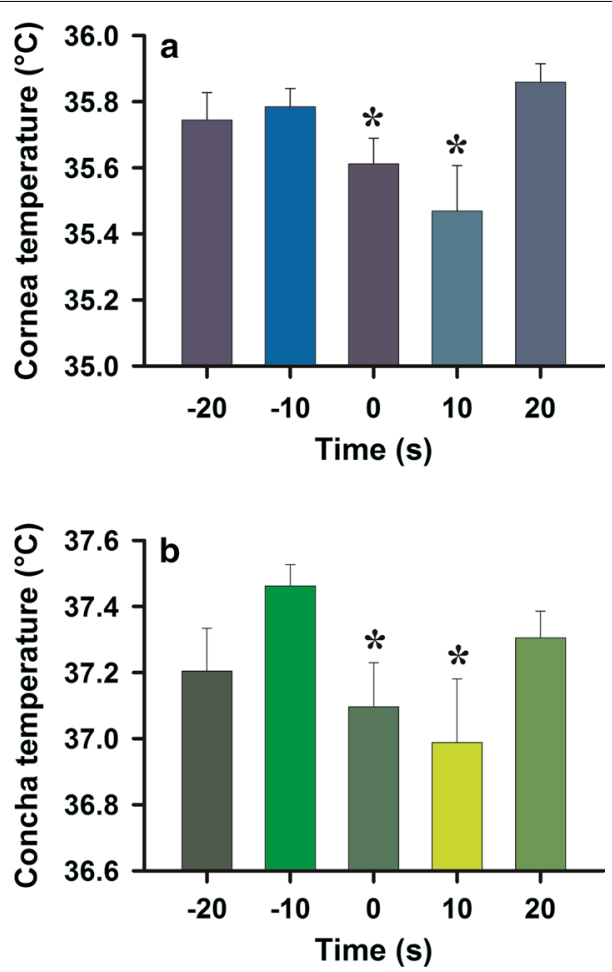

Fig. 5 Average corneal temperature significantly changed around the time of yawning events. a Corneal temperatures were significantly different across the five time points $\left({ }^{*} P<0.01\right)$. Temperatures significantly decreased during yawning and continued to decrease for $10 \mathrm{~s}$. By $20 \mathrm{~s}$ after yawning, temperatures had begun to rise again. b Conchal temperatures were significantly different across the five time points $(* P<0.01)$. Temperatures increased before yawning, supporting the expression of yawning, and significantly decreased during yawning and the following $10 \mathrm{~s}$. Subsequently they rose back to basal levels. All data points are the mean \pm SE of at least 15 thermographic frames

surfaces such as the eye and ear could directly alter brain temperature. Our observations of a mean reduction of $-0.32{ }^{\circ} \mathrm{C}$ in the cornea and $-0.48{ }^{\circ} \mathrm{C}$ in the concha are consistent with the reduction of just over $-0.11{ }^{\circ} \mathrm{C}$ in the cerebral cortex of rats following yawns observed in a previous study [25]. The differences can be explained by the heat gain/loss ratio that follows circulation in blood vessels, as well as by differences in the quantity of blood supply to the brain and face, which are governed by different vascular tones and by evaporation in the paranasal sinuses [51]. Importantly, the corneal surface immediately returned to pre-yawning temperatures because blood in the ophthalmic artery carries heat continuously from inside the cranium, and in the case of the concha, heat-loss primarily results from convection and conduction mechanisms.

Importantly, Sato-Suzuki et al. [52] showed that chemical or electrical stimulation of the paraventricular nucleus of the hypothalamus evoked yawning and shifted EEG activity from delta to theta rhythms. They also showed an association between a drop in blood pressure and skin conductance supporting changes in the sympathetic inhibitory responses. Our results showed changes in the temperature of facial structures due to changes in the blood flow to the head. These changes are closely associated with the loss of heat in the oropharynx due to air flow, and support the validity of the thermoregulatory role of yawning.

\section{Conclusion}

Our results are consistent with a growing number of comparative studies supporting the thermoregulatory theory of yawning [9]. The use of HY rats in this study provides an effective sample population for this investigation because of their high frequency of spontaneous yawning. However, further studies using similar thermal imaging techniques are needed to replicate these findings in other lines or species with more typical yawning patterns.

\section{Methods \\ Animals}

We used seven male HY Sprague-Dawley rats (5 months old, $470 \pm 7 \mathrm{~g}$ ) based on the premise that yawning is a sexually dimorphic pattern (spontaneous yawning rates have been shown to be 20 yawns/h for males, and less than 2 yawns/h for females) [53]. Rats were obtained from the animal room facilities at the Institute of Physiology at Benemérita Universidad Autónoma de Puebla, México, and were maintained under standard conditions with temperature $22 \pm 1{ }^{\circ} \mathrm{C}$ and $30-45 \%$ relative humidity. Animals were housed 2-3 rats/acrylic cage, with free access to balanced rodent pellets (LabDiet, Rodent Diet 5012, USA) and purified water. The light-dark cycle was set to $12: 12$, with lights on at 0700 . All rats were tested between the hours of 1100 and 1300 to avoid circadian changes [30]. All experiments were performed following the NIH Guide for the Care and Use of Laboratory Animals (NIH publications No. 80-23). This research was approved by the local Institutional Animal Care and Use Committee at Benemérita Universidad Autónoma de Puebla.

\section{Experimental design}

We used an infrared camera (Fluke TiR1) for measuring surface temperature in the concha and in the cornea. The camera has a measurement range from -20 to $+150{ }^{\circ} \mathrm{C}$, with a thermographic resolution of $640 \times 480$ pixels. The camera uses SmartView ${ }^{\mathrm{TM}}$ software (Fluke Co., England) for detail assessment of temperatures and is capable of determining the maximum, minimum, and mean 
temperatures of a given area in a single image. Red zones in the concha and cornea were delineated with a $45-\mathrm{mm}^{2}$ ellipse, considering that the surrounding areas are cooler because of the presence of skin covered by fur, as shown for the cornea in Fig. 4, with a black circle surrounding the cornea measured over red areas with higher temperatures and the same pattern with the concha. We used the measurements for the minimum, mean and maximum temperatures because the camera provided high sensitivity and resolution with an accuracy of $0.1{ }^{\circ} \mathrm{C}$. This area was consistent, and results equivalent, when a blind observer performed the procedure. Temperature recordings were included in the analysis only when the images showed an angle of less than $10^{\circ}$ of variation around the position of the nose. We also measured temperatures at the bottom of the observation box to control ambient temperature conditions throughout the experiment because this is an important variable for heat exchange mechanisms.

\section{Procedure}

Rats were transferred to a soundproof room with controlled temperature and humidity, illuminated by two overhead incandescent lamps (220 lx). They were adapted to the observation conditions by living $1 \mathrm{~h}$ for 3 consecutive days in a wooden box $(21 \times 11 \times 7 \mathrm{~cm})$ that partially restrains their movements and allows a clear observation of yawning. This adaptation process is necessary to reduce stress responses on the test day. On the 4th day, we evaluated yawning frequency simultaneously with changes in temperature at the cornea and concha. Under these circumstances, we could take serial thermographs at 10-s intervals. A researcher situated in front of the wooden observation box aligned the infrared camera to line up exactly in front of each rat at a constant distance of $30 \mathrm{~cm}$, allowing us to delineate and measure the same area around the concha and cornea for all measurements. This is an important control to maintain conditions with respect to the heat sources and reflections, including the wooden box itself. Because infrared is invisible to humans, we always recorded a pair of measurements before and after the experimental sessions to measure temperatures under control conditions.

After a 5-min adaptation period, we evaluated spontaneous yawning frequency for $55 \mathrm{~min}$ and manually took thermographic images at roughly 10 -s intervals independently of the behavior for each animal. A second blind observer recorded the time when the image was taken and when yawns occurred using Observer XT software (Noldus, Netherlands).

\section{Statistics}

Offline analyses allowed us to pair each yawning event with changes in the -conchal and corneal temperatures.
All data were evaluated using Sigma-Plot v. 12.0 (Systat software, USA), and the statistical analyses were performed using the statistics module of Sigma-Plot. Comparison tests included a repeated analysis of variance (ANOVA) followed by Tukey's test with $P<0.05$ considered statistically significant.

\section{Abbreviations \\ HY: high-yawning; ANOVA: analysis of variance; NIH: National Institutes of Health.}

\section{Authors' contributions}

JRE and CC conceived and designed the experiments, participated in the acquisition of data, and helped to draft and critically revise the manuscript for intellectual content with ACG. JRE and CC have the responsibility for the final approval of the manuscript. JRE, CC, CAU, AB and ACG contributed to the analysis and discussion of the final draft of the manuscript. All authors read and approved the final manuscript.

\section{Author details \\ ${ }^{1}$ Research Office of the Vice Rectory of Research and Postgraduate Studies, Benemérita Universidad Autónoma de Puebla, 4 Sur \# 104. Col. Centro, 72000 Puebla, Pue., Mexico. ${ }^{2}$ Institute of Physiology, Benemérita Universidad Autónoma de Puebla, Apdo. Postal 5-66, Col. Prados Agua Azul, 72430 Puebla, Pue., Mexico. ${ }^{3}$ Centro Tlaxcala de Biología de la Conducta, Universidad Autónoma de Tlaxcala, Tlaxcala, Mexico. ${ }^{4}$ Psychology Department, SUNY Col- lege at Oneonta, Oneonta, NY, USA.}

\section{Acknowledgements}

We really appreciate the support of Dr. Ygnacio Martínez-Laguna, Vice-rector of Research and Postgraduate Studies and Mtra. Esperanza Morales Pérez, DGPI-BUAP.

\section{Competing interests}

The authors declare that they have no competing interests.

\section{Availability of data and materials}

Data and materials are available from the corresponding author upon request at jose.eguibar@correo.buap.mx.

\section{Consent for publication}

All authors consent for this publication and all experiments were performed in accordance with the Guideline for the Care and Use of Laboratory Animals of the $\mathrm{NIH}$.

\section{Ethical approval}

All experiments were approved by Institutional Animal Care and Use Committee (IACUC) of Benemérita Universidad Autónoma de Puebla and were performed in accordance with the Guideline for the Care and Use of Laboratory Animals of the $\mathrm{NIH}$.

\section{Funding}

This work was supported by Consejo Nacional de Ciencia y Tecnología (CONACyT) Grants Nos. 243247 and 243233 to J.R.E. and C.C., respectively. The study was also supported by Grant VIEP-SALUD 2016 to J.R.E. and C.C. and by the PRODEP-SEP Grant to Cuerpo Académico en Neuroendocrinología BUAPCA-288. This work was part of the thesis CAU for partial fulfillment of his PhD requirements and he was the beneficiary of a scholarship from CONACYT.

Received: 5 July 2016 Accepted: 27 December 2016

Published online: 03 January 2017

References

1. Barbizet J. Yawning. J Neurol Neurosurg Psychiatry. 1958;21:203-39. 
2. Walusinski O. Historical perspectives. In: Walusinski O, editor. The mystery of yawning in physiology and disease. Paris: Karger; 2010. p. 1-160.

3. Baenninger R. Some comparative aspects of yawning in Betta splendens, Homo sapiens, Panthera leo, and Papio sphinx. J Comp Psychol. 1987;101:349-54.

4. Daquin G, Micallef J, Bin O. Yawning. Sleep Med Rev. 2001;5:299-312.

5. Guggisberg AG, Mathis J, Schnider A, Hess CW. Why do we yawn? Neurosci Biobehav Rev. 2010;34:1267-76.

6. Provine RR, Tate $\mathrm{BC}$, Geldmacher LL. Yawning: no effect of 3-5\% $\mathrm{CO}_{2}$, $100 \% \mathrm{O}_{2}$, and exercise. Behav Neural Biol. 1987;48:382-93.

7. Gallup AC, Gallup GG Jr. Yawning as a brain cooling mechanism: Nasal breathing and forehead cooling diminish the incidence of contagious yawning. Evol Psychol. 2007;5:92-101.

8. Gallup AC, Gallup GG Jr. Yawning and thermoregulation. Physiol Behav. 2008:95:10-6.

9. Gallup AC, Eldakar OT. The thermoregulatory theory of yawning: what we know from over 5 years of research. Front Neurosci. 2012;2013(188):1-12. doi:10.3389/fnins.2012.00188.eCollection.

10. Baker MA. Brain cooling in endotherms in heat and exercise. Annu Rev Physiol. 1982;44:85-96.

11. Heusner AP. Yawning and associated phenomena. Physiol Rev. 1946:26:156-68

12. Corey P, Shoup-Knox ML, Gordis EB, Gallup GG Jr. Changes in physiology before, during, and after yawning. Front Evol Neurosci. 2012;3:1-11. doi:10.3389/fnevo.2011.00007.

13. Askenasy JJM. Is yawning an arousal defense reflex? J Psychol. 1989;123:609-21.

14. Bhangoo KS. Why the yawn? N Engl J Med. 1974;290:1027-8.

15. Cabanac M, Brinnel H. Blood flow in the emissary veins of the human head during hyperthermia. Eur J Appl Physiol. 1985;54:172-6.

16. Zenker W, Kubik S. Brain cooling in humans-anatomical considerations. Anat Embryol. 1996;193:1-13.

17. Takeda Y, Hashimoto H, Fumoto K, Danura T, Naito H, Morimoto N, Katayama H, Fushimi S, Matsukawa A, Ohtsuka A, Morita K. Effects of pharyngeal cooling on brain temperature in primates and humans: a study for proof of principle. Anesthesiology. 2012;117:117-25.

18. Koritzer R, Hack G. The paranasal sinuses: an active residual system. Am J Phys Anthropol. 2002;117:96-7.

19. Sedlmayr JC, Witmer LM. The avian suborbital air sac and its potential role in brain cooling in birds and other dinosaurs. Am Zool. 2001;240:1206.

20. Gallup AC, Eldakar OT. Contagious yawning and seasonal climate variation. Front Evol Neurosci. 2011;2011(3):1-4. doi:10.3389/ fnevo.2011.00003.eCollection.

21. Gallup AC, Miller ML, Clark AB. Yawning and thermoregulation in budgerigars, Melopsittacus undulatus. Anim Behav. 2009;77:109-13.

22. Gallup AC, Miller RR, Clark AB. Changes in ambient temperature trigger yawning but not stretching in rats. Ethology. 2010;116:145-53.

23. Campos FA, Fedigan LM. Behavioral adaptations to heat stress and water scarcity in white-faced capuchins (Cebus capucinus) in Santa Rosa National Park, Costa Rica. Am J Physiol Anthropol. 2009;138:101-11.

24. Massen JJM, Dusch K, Eldakar OT, Gallup AC. A thermal window for yawning in humans: yawning as a brain cooling mechanism. Physiol Behav. 2014:130:145-8

25. Shoup-Knox ML, Gallup AC, Gallup GG, McNay EC. Yawning and stretching predict brain temperature changes in rats: support for the thermoregulatory hypothesis. Front Evol Neurosci. 2010;2010(2):1-5. doi:10.3389/fnevo.2010.00108.eCollection.

26. Miller ML, Gallup AC, Vogel AR, Clark AB. Handling stress initially inhibits, but then potentiates, yawning in budgerigars (Melopsittacus undulatus). Anim Behav. 2010;80:615-9.

27. Urbá-Holmgren R, Trucios N, Holmgren B, Eguibar JR, Gavito A, Cruz G, Santos A. Genotypic dependency of spontaneous yawning frequency in the rat. Behav Brain Res. 1990;40:29-35.

28. Holmgren B, Urbá-Holmgren R, Trucios N, Zermeño N, Eguibar JR. Association of spontaneous and dopaminergic-induced yawning and penile erections in the rat. Pharmacol Biochem Behav. 1985;22:31-5.

29. Eguibar JR, Cortes C, Isidro O, Ugarte A. Central administration of oxytocin differentially increases yawning, penile erections and scratching in
high-(HY) and low-yawning (LY) sublines of Sprague-Dawley rats. Pharmacol Biochem Behav. 2015;134:6-11.

30. Anías J, Holmgren B, Urbá-Holmgren R, Eguibar JR. Circadian variation of yawning behavior. Acta Neurobiol Exp. 1984;44:179-86.

31. Holmgren B, Budelli R, Urbá-Holmgren R, Eguibar JR, Holmgren M, Baz-Tellez G, Anías J. Food anticipatory yawning rhythm in the rat. Acta Neurobiol Exp. 1991;51:97-105.

32. Moyaho A, Rivas-Zamudio X, Ugarte A, Eguibar JR, Valencia J. Smell facilitates auditory contagious yawning in stranger rats. Anim Cogn. 2015;18:279-90.

33. Eguibar JR, Romero-Carbente JC, Moyaho A. Behavioral differences between selectively bred rats: $D_{1}$ versus $D_{2}$ receptors in yawning and grooming. Pharmacol Biochem Behav. 2003;74:827-32.

34. Urbá-Holmgren R, Santos A, Holmgren B, Eguibar JR. Two inbred rat sublines that differ in spontaneous yawning behavior also differ in their responses to cholinergic and dopaminergic drugs. Behav Brain Res. 1993:56:155-9.

35. Eguibar JR, Barajas M, Moyaho A. Genotype-dependent effect of ACTH124 on grooming and yawning in two inbred strains of rats. Neuropeptides. 2004;38:283-8.

36. Xue X, Liu J. Mechanisms interpretation of the biological brain cooling and its inspiration on bionic engineering. J Bionic Eng. 2011:8:207-22.

37. Weissenböck NW, Weiss CM, Schwammer HM, Kratochvil H. Thermal windows on the body surface of African elephants (Loxodonta africana) studied by infrared thermography. J Therm Biol. 2010;35:182-8.

38. Gallup GG Jr, Gallup AC. Excessive yawning and thermoregulation: two case histories of chronic, debilitating bouts of yawning. Sleep Breath. 2010;14:157-9.

39. Kiyatkin EA, Brown PL, Wise RA. Brain temperature fluctuation: a reflection of functional neural activation. Eur J Neurosci. 2002;16:164-8.

40. Lemons DE, Chien S, Crawshaw LI, Weinbaum S, Jiji LM. Significance of vessel size and type in vascular heat transfer. Am J Physiol. 1987:253:R128-35.

41. Grayson J. Internal calorimetry in the determination of thermal conductivity and blood flow. J Physiol (Lond). 1952;118:54-72.

42. Yablonskiy DA, Ackerman JJ, Raichle ME. Coupling between changes in human brain temperature and oxidative metabolism during prolonged visual stimulation. Proc Natl Acad Sci USA. 2000;97:7603-8.

43. Chen MM, Holmes KR. Microvascular contributions in tissue heat transfer. Ann NY Acad Sci USA. 1980:335:137-50.

44. Pennes HH. Analysis of tissue and arterial blood temperature in the resting human forearm. J Appl Physiol. 1948;1:93-122.

45. Weinbaum S, Jiji LM. A new simplified bioheat equation for the effect of blood flow on local average tissue temperature. J Biomech Eng. 1985;107:131-9.

46. Weinbaum S, Jiji LM, Lemons DE. Theory and experiment for the effect of vascular microstructure on surface tissue heat transfer. Part I. Anatomical foundation and model conceptualization. J Biomech Eng. 1984;106:321-30

47. Gordon CJ. Thermal biology of the laboratory rat. Physiol Behav. 1990:47:963-91.

48. Gordon CJ. Thermal physiology of laboratory rat mice: Defining thermoneutrality. JTherm Biol. 2012;37:654-85.

49. Sadegh Firoozan M, Porkhial S, Salamani Nejad A. Effect of tissue and atmosphere's parameters on human eye temperature distribution. J Therm Biol. 2015;47:51-8.

50. Caputa M, Perrin G, Cabanac M. Reversal of human ophthalmic vein blood flow: selective cooling of the brain. C R Hebd Seances Acad Sci Ser D Sci Nat. 1978:D287:1011-4.

51. Gallup AC, Hack GD. Human paranasal sinuses and selective brain cooling: a ventilation system activated by yawning? Med Hypotheses. 2011:77:970-3.

52. Sato-Suzuki I, Kita I, Oguri M, Arita H. Stereotyped yawning responses induced by electrical and chemical stimulation of paraventricural nucleus of the rat. J Neurophysiol. 1998;80:515-9.

53. Holmgren B, Urbá-Holmgren R, Aguiar M, Rodríquez R. Sex hormone influences on yawning behavior. Acta Neurobiol Exp. 1980;40:515-9. 